\title{
DETERMINISANJE KLJUČNIH INDIKATORA INTELEKTUALNOG KAPITALA ORGANIZACIJE „KOJA UČl”
}

\author{
Stanojković Srđan ${ }^{1}$, \\ Petra Balaban², \\ Dragan Cvetković ${ }^{3}$
}

\author{
${ }^{1}$ Beogradska politehnika, \\ Beograd \\ 2Visoka tehnička škola strukovnih \\ studija u Novom Sadu \\ ${ }^{3}$ Singidunum Univerzitet, \\ Beograd
}

Correspondence:

Srđan Stanojković

e-mail:

ihbinsrdjan@gmail.com

\section{Rezime:}

Osnovni resurs organizacije jeste znanje, kome poseban značaj daje aktuelni trenutak. Visok stepen razvoja i prisutnost tehnologije u svim porama života diktira novi način poslovanja i razmišljanja, menjajući društvenu svest. Razvoj informacione tehnologije, celokupno poslovanje oslanja na neopipljive resurse. Vlasnici neopipljivih komponenti poslovanja jesu zaposleni koji svojim znanjem čine organizacionu kulturu. Organizaciona kultura jeste prepoznatljivi pečat svake organizacije i čini jezgro njene kompetentnosti kao osnov za postizanje konkurentske prednosti. Obim intelektualnog kapitala organizacije u srazmeri je sa njenom sposobnošću kreiranja superiorne vrednosti u odnosu na konkurenciju. Cilj ovog naučnoistraživačkog projekta je determinisanje ključnih indikatora intelektualnog kapitala karakterističnih za poslovanje grafičke industrije.

Ključne reči:

znanje, intelektualni kapital, IT, kontrolne karte, grafička organizacija koja uči.

\section{UVOD}

U savremenom okruženju, intelektualni capital postao je odlučujući organizacioni resurs kojim se stiče konkurentska prednost poslovanja. Intelektualni kapital sadržan je u svim organizacionim nivoima, od baznih poslovnih procesa, do najvišeg nivoa organizacije. On se može proceniti, a njime se i koordinira, čime unapređujemo konkurentnost organizacije. U današnjem poslovanju sinergijski su povezani intelektualni kapital i nove tehnologije. Značajna karakteristika novih tehnologija jeste njihov nezamenljiv uticaj na celokupne poslovne odnose organizacije, kako unutar nje, tako i u njenom okruženju. Savremeno poslovanje se ne može zamisliti bez integracije, računara, interneta i telekomunikacija. Svojom prirodom, nove tehnologije menjaju procedure i načine poslovanja u samim organizacijama i uslovljavaju povezanost organizacije sa eksternim faktorima (globalizacija informacija).

Danas su informacione tehnologije ključni faktor organi-zacionog dizajna i performansi u poslovanju. Uslov za korišćenje informacionih tehnologija jeste znanje o njihovoj upotrebi. Samo organizacija „koja uči” obezbeđuje pretpostavku za uspešno poslovanje organizacije i zadovoljenje potreba zainteresovanih strana. Intelektualni kapital predstavlja 
interakciju između čoveka, strukture i tržišta. Cilj istraživanja je težiti što racionalnijem izboru metode za vrednovanje (konkretno, vreduje se intelektualni kapital). U ovom naučno-istraživačkom projektu determinišu se ključni indikatori intelektualnog kapitala u "grafičkim organizacijama koje uče”.

\section{ZNANJE}

\subsection{Opšte}

„Osnovni resursi u ekonomiji nisu više kapital, prirodni resursi i radna snaga, to jeste i biće znanje” (Peter Drucker). Ovaj mislilac informatičku eru vizinarski naziva „revolucijom znanja” (1959) i uvodi pojam „radnika znanja" (knowledge worker). Time definiše najveću radnu grupaciju koja će dominantno obeležeti i nositi aktivnosti nove ekonomije i koja će biti oslonac modernog društva i poslovanja. Karakteristike radnika znanja su njegova stručnost, veštine, znanje i formalno obrazovanje [2].

\subsection{Elementi znanja}

Podaci i činjenice oko nas deo su svakodnevnice i prepoznajemo ih kao bljesak nekih nepoznatih zbivanja, bez konkretne međusobne veze. Kada podatak dobije neko konkretno značenje - postaje informacija. Sakupljene i organizovane informacije povezane razumnim vezama daju znanje.

Hijerhija znanja definiše razlike između podataka, informacija i znanja, te razlikujemo:

- Podatak - neorganizovanu i neobrađenu činjenicu, bez posebnog smisla. On opisuje samo deo onoga što se dešava bez objašnjenja ili davanja značaja događaju. Podatak je osnov za formiranje informacije;

- Informaciju - ima svoje značenje, svrhu i relevantnost. Informacija daje značaj podatku.

- Znanje - ono što predstavlja svrsishodno skupljanje informacija koje bivaju razumno povezane i time dobijaju svoju korisno-upotrebnu vrednost.

Znanje, eksplicitno ili prećutno, individualno ili kolektivno, oduvek je predstavljalo osnovu ljudskog napretka. Primena znanja jeste osnovni zadatak procesa menadžmenta znanja organizacije. Suština uspešnog programa menadžmenta znanja je primena postojećeg znanja organizacije tako da ono uvećava značaj i vrednost organizacije. Aktuelni oblik organizovanja poslovnog sistema znanje sagledava i kao input i kao output organizacije [2].
Svaka organizacija poseduje određeni nivo znanja. Upravljanje znanjem podrazumeva pretvaranje individualnog znanja zaposlenih u kolektivno i organizaciono znanje koje će biti dostupno svim članovima organizacije.

Znanje se permanetno uvećava i prilagođava okolnostima.

\section{INTELEKTUALNI KAPITAL}

\subsection{Opšte}

„Intelektualni kapital čine znanja koja postoje unutar organizacije i kojima se koriste za kreiranje konkurentskih prednosti - drugim rečima, to je zbir svega što svi zaposleni znaju i što izoštrava konkurentske prednosti poduzeća" (Bontis, 1996) [4].

Srž intelektualnog kapitala organizacije jeste znanje kao najbitniji resurs organizacije. U novije vreme stvaraju se nove delatnosti koje se oslanjaju isključivo na znanje kao na osnovni resurs u stvaranju tržištne predosti i ostvarenju dodatne vrednosti. Bez obzira što spada u „nevidljivu imovinu organizacije”, intelektualni kapital (tj. sveukupno znanje organizacije) zauzima sve veći deo vrednosti organizacije i čini prepoznatljivi brend interesantan za kupce. Nosilac intelektualnog kapitala i stožer ovog resursa jeste čovek [3].

Intelektalni kapital jeste složena kategorija koju čine materijalni i nematerijalni elementi. Uz pomoć njih, organizacija postiže očuvanje održivog razvoja i konkurentnosti (upotreba znanja u stvaranju novostvorene vrednosti).

Intelektalni kapital čine: a) ljudski kapital - definisan kao znanje, iskustvo, sposobnost, umeće, kreativnost i inovativnost pojedinca; b) strukturni kapital - nastaje kao rezultat procesa ljudskog kapitala u prošlosti; c) relacijski kapital - uključuje odnose sa kupcima i dobavljačima, brend, reputacija, imidž (Slika 1).

Neopipljivost kapitala otežava proces njegove kvantifikacije i merenja. Glavne pošteškoće pri merenju intelektualnog kapitala su: identifikovanje, definisanje i prepoznavanje resursa koje je potrebno meriti. One se prevazilaze utvrđivanjem nematerijalnih resursa najvažnijih za strateški značaj i uspeh preduzeća, kao i utvrđivanje komponenti intelektualnog kapitala koje najviše utiču na ostvarenje ciljeva poduzeća. Preporučuje se da svaka organizacija razvije vlastiti proces vrednovanja intelektualnog kapitala u zavisnosti od svojih potreba i specifičnosti poslovane struke $[3,4]$. 


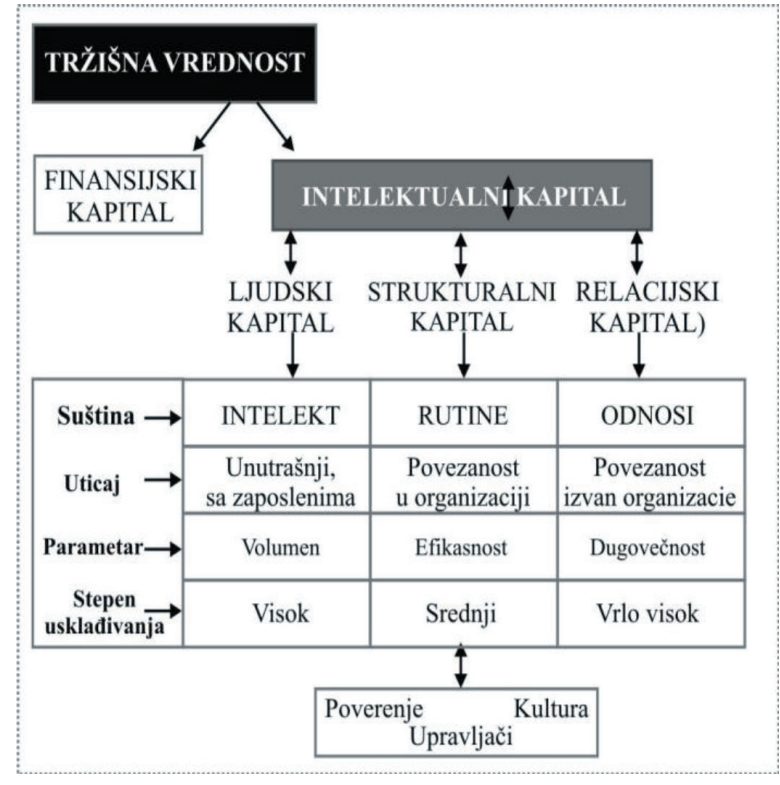

Slika 1. Mesto i klasifikacija intelektualnog kapitala prema Bontisu [4].

\subsection{Indikatori intelektualnog kapitala u grafičkim organizacijama „koje uče”}

Aktuelno poslovanje traži od organizacije prepoznavanje zahteva ambijenta u kome ona obitava (zainteresovane strane, interesne grupe ili društva itd.). Da bi organizacija brzo reagovala na raznolike promene okruženja, mora i sama pretrpeti određene radikalne promene $\mathrm{u}$ svojoj strukturi, za šta joj je neophodno znanje.

Najčešće radikalne promene u organizaciji su:

- aktivnosti organizacije koja uči;

- aktivnosti elektronskog poslovanja;

- aktivnosti implementacije TQM-a;

- aktivnosti reinženjeringa poslovnih procesa itd. [2].

\subsection{1. „Organizacija koja uči”}

„Organizacija koja uči” (u daljem tekstu bez navodnica) nije poseban model organizacione strukture, nego je to osobina oblika oraganizovanja koji može imati različite pojavne oblike (procesni, funkcionalni, divizionalni, mrežni, itd.) sa posebnim mentalnim opredeljenjem.

Organizacija koja uči (učeća organizacija) u stanju je da kreira znanje sistematskim učenjem „od drugih”. Ona prepoznaje aktuelne stalne promene i time stiče iskustvo u upravljanju i donošenju odluka. Time se njene performanse stalno poboljšavaju [3].

Preovladava mišljenje da su najuspešnije organizacije one koje uče i poseduju sposobnost da brže uče od konkurencije. Ova osobina organizacije (pored sposobnosti da na efikasan način upravlja znanjem koje poseduje) omogućava stabilan položaj u svojoj poslovnoj klasi. I za korišćenje znanja, i za učenje, neophodani elementi su stvaranje novog znanja i sposobnost njegove primene kao deo koncepta menadžmenta znanja. Kod organizacije koja uči, svi zaposleni stalno razvijaju sposobnost kreiranja rezultata, neguju nove obrasce ponašanja i kontinuirano uče i stiču novo znanje (Slika 2).

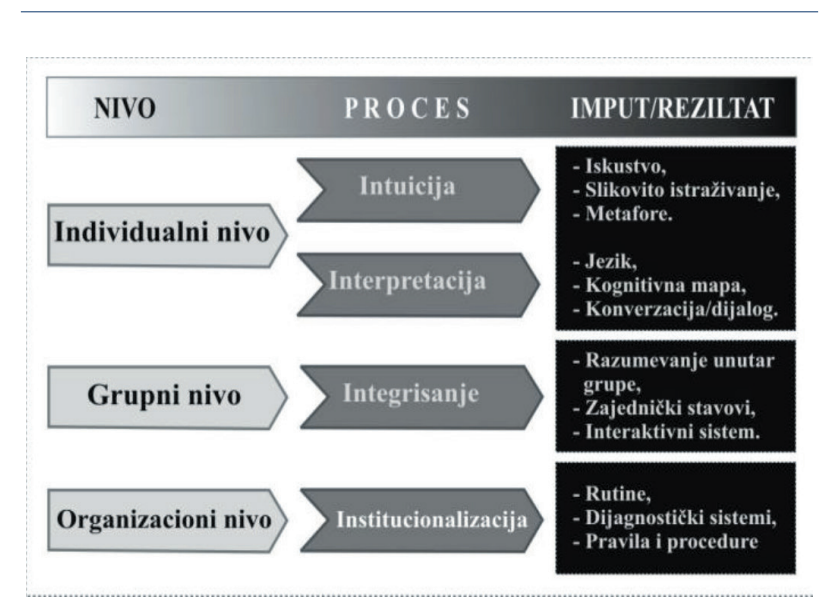

Slika 2. Okvir organizacionog učenja [3]

(modifikovano od strane autora)

Aktivnosti koje razlikuju tradicionalnu organizaciju od organizacije koja uči su: sistematsko razmišljanje; lično usavršavanje; mentalni modeli; zajednička vizija; timsko učenje itd.

Uslov da bi organizacija bila ona koja uči je da koristi menadžment znanja, dok menadžment znanja funkcionalno zavisi od organizacije koja uči. Očigledna je zavisnost i neophodnost ova dva sistema, organizacionog učenja i menadžmenta znanja u savremenom poslovanju [2].

\section{INFORMACIONE TEHNOLOGIJE}

Suština novih tehnologija jeste njihov upliv na celokupne poslovne odnose i promene koje iziskuje njihova upotreba (a bez njih se ne može). U savremenom trenutku nove tehnologije su temelj u determinisanju novih proizvoda prema aktuelnom zahtevu kupaca. Savremeno poslovanje se ne može zamisliti bez integracije, računara, interneta i telekomunikacija. Svojom prirodom, nove tehnologije menjaju procedure i načine poslovanja u samoj organizaciji i uslovljavaju specifičnu povezanost organizacije sa eksternim faktorima (globalizacija informacija).

Osnovni produkt informacionih tehnologija, koji neposredno utiče na organizaciju, jeste elektronsko 
poslovanje, kao sinonim za savremeno poslovanje. Ono predstavlja skup poslovnih aktivnosti koje se odvijaju posredstvom informaciono-komunikacionih tehnologija (internet kao osovina komunikacije).

Glavne aktivnosti elektronskog načina poslovanja su:

- Optimizacija svih poslovnih procesa (marketinga, prodaje, proizvodnje, distribucije, nabavke i dopune zaliha, naplate itd.);

- Unapređenje odnosa sa ciljnom grupom (klijenti, zapo-sleni, dobavljači, distibuteri);

- Unapređenje logističkih poslovnih odnosa (banke, advokatske službe, računovodstvene agencije, reklamne agencije zakonodavstvo).

Mehanizam funkcionisanja elektronskog poslovanja sadržan je u odnosu provajder (proizvođač) i korisnik (klijent), gde postoji više varijanti funkcionisanja (Slika 3).

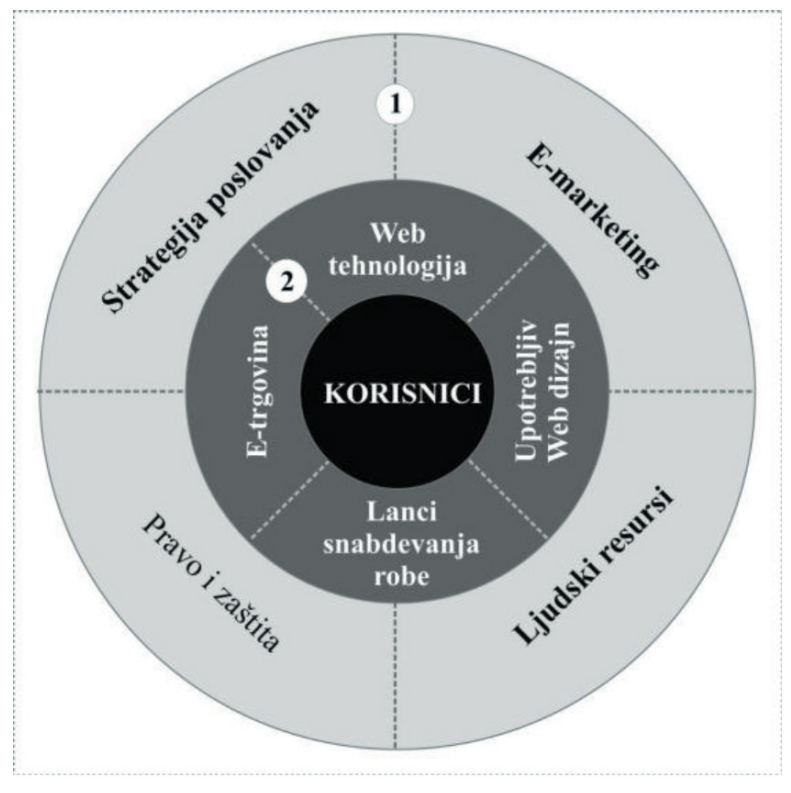

Slika 3. Krug elektronskog poslovanja (modifikovano od strane autora).

Savremeno poslovanje zahteva prilagođavanje organiza-cione strukture i zaposlenih novom načinu poslovanja (dostupnost informacijama), gde su na centralnom mestu procesa, znanje i menadžment znanja [2].

Početni uslov za korišćenje informacionih tehnologija u organizaciji jeste mentalno-kulturološki nivo poslovanja organizacije tj. organizacija mora biti - ona koja uči [1].

\section{KONTROLNA KARTA}

Statistička metoda Kontrolna karta predstavlja efikasan alat za uspostavljanje, regulisanje i upravljanje procesom, čiji je produkt kvalitet proizvoda i procesa.

Ovaj alat koristi se za:

- usavršavanje i poboljšanje tehnološkog procesa rada sa stanovišta kvaliteta;

- upravljanje kvalitetom procesa rada i poslovanja;

- faznu kontrola kvaliteta proizvoda;

- analize sistema grešaka iz tehnološkog procesa;

- u serijskoj i masovnoj proizvodnji itd.

$\mathrm{Na}$ kontrolnij karti razlikuju se tri osnovne linije: Centralna linija, CL (predstavlja srednju nominalnu vrednost, X0); linija gornje kontrolne granice, GKG; linija donje kontrolne granice, DKG. Kontrolna karta može posedovati još dve pomoćne linije ispod i iznad gornje i donje kontrolne granice. One definišu donju i gornju upozoravajuću granicu (DUG i GUG) i predstavljaju vrednosti koje signaliziraju da proces ima tendenciju nestabilnosti, odnosno da je potrebno povećanom pažnjom pratiti rezultate narednih merenja (Slika 4).

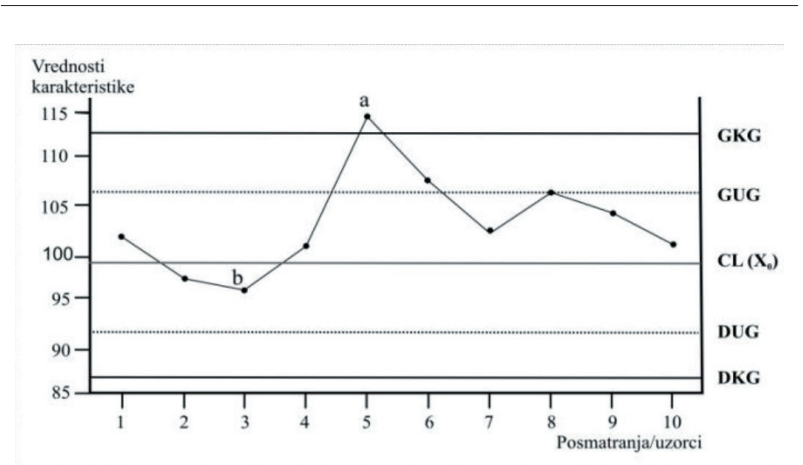

Slika 4. Opšti grafički prikaz kontrolne karte.

Opšti postupak izrade kontrolnih karata je sledeći:

- Odabir karakteristika kvaliteta objekta;

- Određivanje načina biranja: veličine uzorka i vremena uzimanja uzorka;

- Odabiranje statističkih mera koje će se primeniti $\mathrm{u}$ izradi karata (x, R, $\sigma, \mathrm{p}, \mathrm{m}, \mathrm{c}, \mathrm{u})$;

- Izdrada kontrolne liste kontrolnih karata [5].

Praktično, formira se plan kontrolisanja procesa koji sadrži vreme i lokaciju uzimanja uzoraka. Sledi merenje (ocena) vrednosti izabranih karakteristika indikatora $\mathrm{i}$ njihovo obračunavanje predviđenom procedurom i formulama. Dobijeni rezultati unose se u kontrolnu kartu, čime ona postaje pregledna slika kvaliteta u vremenskom 
odvijanju procesa (grafički se izrađuje). Ukoliko su izračunate vrednosti unutar kontrolnih granica (tj. kontrolnih linija) smatra se da je proces stabilan (tj. pod statističkom kontrolom). $U$ suprotnom je proces nestabilan i van je statističke kontrole [5].

\section{PROCES ISTRAŽIVAČKOG PROJEKTA}

\subsection{Opšte}

U naučno-istraživačkom projektu determinisani su indikatori intelektualnog kapitala u grafičkim organizacijama koje uče. Primenjen je princip kvalitativnog istraživanja u razumevanju pojave i metoda malog uzorka do 40 uzorkovanih objekata koji se bave grafičkom delatnošću. Istraživanje je sprovedeno korišćenjem upitnika. Anketni upitnik sadrži 100 pitanja na čije se odgovore došlo intervjuom sa odabranim grafičkim organizacijama. U ovakvom tipu istraživanja relevantnim uzorkom smatra se stopa povratnih informacija od 20\% (Kelton, 1983.). Upitnik je naslovljen najvišem rukovodstvu organizacije i menadžmentu grafičkih organizacija ovih prostora.

\subsection{Struktura naučno-istraživačkog projekta}

\subsubsection{Faze naučno-istraživačkog projekta}

Intervjuisane su vodeće grafičke organizacije na ovim prostorima.

U prvoj fazi istraživanja definisan je upitnik i broj pitanja. Odabrano je 10 pitanja i 10 potpitanja, tako se zbirno dobilo 100 pozicija koje su uzorkovane u 8 organizacija tj. ukupno 800 karakteristika. Pri odgovoru na pitanja, vrednost se ocenjivala procentualno (0-100\%) (Slika 5).

$\mathrm{U}$ drugoj fazi je na dobijene vrednosti primenjen metod Kontrolna karta, čime su determinisani indikatori intelektualnog kapitala u organizacijama grafičke industrije koji imaju najmanja odstupanja od centralnih linija metode. Proračun je urađen i za X-kartu i za R-kartu korišćenjem Excel aplikacije, dok je kontrolna karta grafički prikazana softverom Corel Draw.

U trećoj fazi je na osnovu rezultata istraživanja grafički prikazana determinacija ključnih indikatora intelektualnog kapitala, njihova tendencija i očekivanja u grafičkim organizacijama Srbije. Na taj način date su smernice i pravci koje treba slediti u daljem razvoju grafičke industrije. Grafički prikaz rađen je softverom Corel Draw (Slika 6).

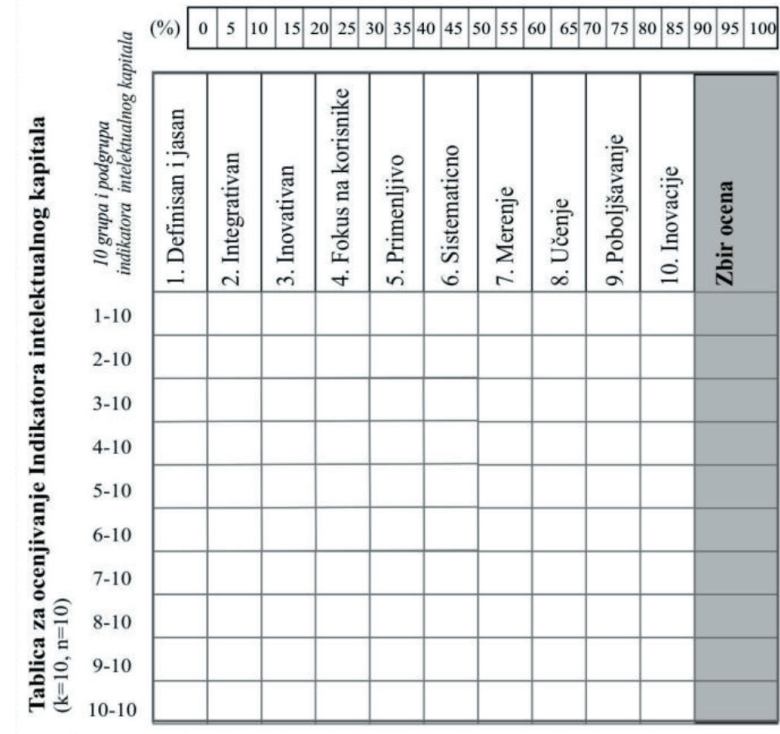

Slika 5. Prikaz izgleda tabele za ocenu indikatora intelektualnog kapitala u grafičkoj industriji Srbije.

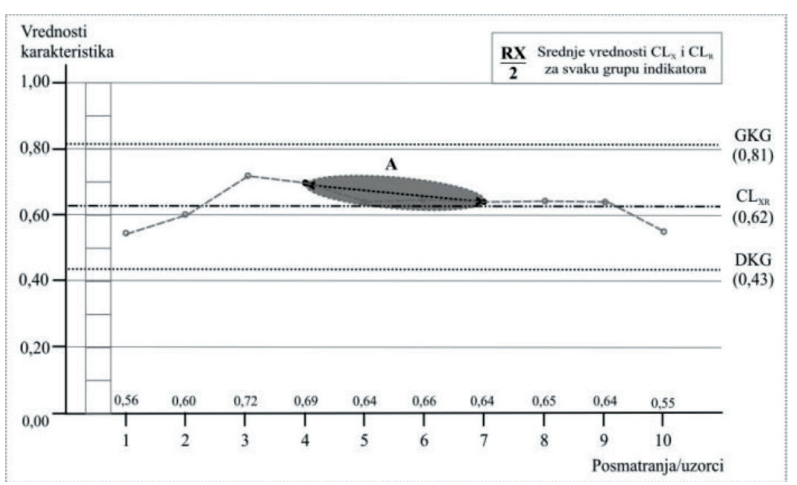

Slika 6. Rangiranje ključnih indikatora; A-Zona generisanja ključnih indikatora intelektualnog kapitala.

\subsection{Funkcija i oblici ključnih indikatora intelektualnog} kapitala specifičnih za grafičku industriju

Ključni indikatori intelektulnog kapitala grafičkih organizacija prepoznati su u grupi kriterijuma Paradigma modela izvrsnosti, specifičnom za grafičku industriju i glase: Kontinualna poboljšanja i inovacije. Ovi kriterijumi su odabrani zbog činjenice da njih može da primeni samo organizacija koja uči i teži poslovnoj izvrsnosti.

Suština indikatora jeste da prikažu način na koji se organizuje proces učenja od drugih i preduzimaju proboji, priraštanja poboljšanja i inovacije mobilizacijom ljudi, i korišcenje TQM alata u grafičkim organizacijama.

Oblici indikatora intelektualnog kapitala grafičke organizacije moraju ispuniti sledeći zahtev - prikazati 
kroz grupe indikatora intelektualnih kapitala (u daljem tekstu GIK) kako organizacija uči od drugih i kako sprovodi poboljšanja $\mathrm{i}$ inovacije $\mathrm{u}$ sledećim aktivnostima $\mathrm{i}$ područjima:

GIK 1 - Izbor, merenje i analize internih informacija koje podupiru ključne procese i poboljšavaju performanse grafičke organizacije;

GIK 2 - Izbor, merenje i analiza eksternih informacija iz organizacija svetskog nivoa delatnosti i/ili najbolje svetske klase (benčmarking), koje služe kao orijentacija za poboljšanje performansi grafičke organizacije;

GIK 3 - Primena IT pozitivno doprinosi procesu stvaranja vrednosti i oslobađanju od prošlosti, i uspostavljanje procesa učenja (od drugih grafičkih organizacija ili iz sopstvenih iskustava);

GIK 4 - Sprovođenje programa oslobađanja od nepotrebne prošlosti i proboja prema novim performansama u grafičku industriju (novi poslovni moral, privatizacija, reinženjering, ISO 9001, promena mentaliteta, nova tržišna i razvojna orjentacija, nova vizija, misija, ciljevi itd.).

GIK 5 - Organizaciona šema za priraštajna poboljšanja (procesa, proizvoda, usluga, sistema veza sa društvom) u koja se uključuju zaposleni grafičke organizacije, kao i kupci, partneri itd.;

GIK 6 - Organizaciona šema za inovacije i kreativne inovacije (procesa, proizvoda, sistema i veza sa društvom) u koje se uključuju zaposleni grafičke organizacije, kao i kupci i partneri upućeni na nju;

GIK 7 - Primena internih i eksternih provera sistema kvaliteta za utvrđivanje neusaglašenosti za preduzimanje korektivnih i preventivnih mera i prilika za poboljšanja ili inovacije specifičnih za grafičku industriju;

GIK 8 - Primena modela samoocenjivanja u ostvarivanju stepena izvrsnosti i nalaženju područja za poboljšanja ili inovacije karakterističnih za grafičku industriju;

GIK 9 - Primena TQM alata na grafičku organizaciju;

GIK 10 - Utvrđivanje efekata dodatnih vrednosti od poboljšanja ili inovacija grafičke organizacije [1].

\subsection{Rezultati naučno-istraživačkog projekta}

\subsubsection{Analiza}

Bazne kriterijume Kontinualna poboljšanja i inovacije čini 100 uzoraka svrstanih u 10 grupa sa po 10 uzorkovanih pozicija. Uzorkovano je 800 karakteristika koje zajedno čine celokupan proces aktivnosti prepoznavanja indikatora intelektalnog kapitala grafičkih organizacija.
U daljem postupku obračuna, maksimalna referenca je bila: ukoliko neka karakteristika prelazi zadate kontrolne granice, time smanjuje i šanse indikatora za njegov odabir kao ključnog indikatora intelektualnog kapitala. U proračunu centralnih linija, donjih i gornjih kontrolnih granica, raspona i aritmetičkih sredina kontrolnih karata, korišćena je tabela P2 (str. 282 [5]) sa vrednostima: $n=10$; $\mathrm{A} 2=0,308 ; \mathrm{D} 3=0,223 ; \mathrm{D} 4=1,777$. Napomena: primenjuju se kontrolne karte za male uzorke koje sadrže do 10 primeraka $(\mathrm{n} \leq 10)$ [5].

Statističkom metodom i obračunom vrednosti dobijenih intervjuom, a u odnosu na CLX i CLR (Slike 4, 6), dobijene su sledeće vrednosti odstupanja u odnosu na dozvoljene granice:

- GIK 1, ispod dozvoljene granice 2 vrednosti, bez odstupanja iznad dozvoljene granice (prosečna vrednost grupe je $C L X=0,820, C L R=0,295$ );

- GIK 2, ispod dozvoljene granice 2 vrednosti, iznad dozvoljene granice 1 vrednost (prosečna vrednost grupe je $C L X=0,813$, $C L R=0,380$ );

- GIK 3, ispod dozvoljene granice 1 vrednost, bez odstupanja iznad dozvoljene granice (prosečna vrednost grupe je $C L X=0,833$, $C L R=0,600$ );

- GIK 4, ispod dozvoljene granice 1 vrednost, iznad dozvoljene granice 2 vrednosti (prosečna vrednost grupe je $\mathrm{CLX}=0,810$, $\mathrm{CLR}=0,585$ );

- GIK 5, ispod dozvoljene granice 2 vrednosti, bez odstupanja iznad dozvoljene granice (prosečna vrednost grupe je $\mathrm{CLX}=0,733$, $\mathrm{CLR}=0,550$ );

- GIK 6, ispod dozvoljene granice 1 vrednost, iznad dozvoljene granice 1 vrednost (prosečna vrednost grupe je $\mathrm{CLX}=0,760$, $\mathrm{CLR}=0,550$ );

- GIK 7, ispod dozvoljene granice 2 vrednosti iznad dozvoljene granice 3 vrednosti (prosečna vrednost grupe je $C L X=0,848, C L R=0,430$ );

- GIK 8, ispod dozvoljene granice 2 vrednosti iznad dozvoljene granice 2 vrednosti (prosečna vrednost grupe je $C L X=0,777$, $C L R=0,525$ );

- GIK 9, ispod dozvoljene granice 2 vrednosti, iznad dozvoljene granice 2 vrednosti (prosečna vrednost grupe je CLX $=0,760$, CLR $=0,525$ );

- GIK 10, ispod dozvoljene granice 1 vrednost, bez odstupanja iznad dozvoljene granice (prosečna vrednost grupe je $C L X=0,843$, CLR $=0,265$ ).

Daljim proračunom izračunata je vrednost zbirne aritmetičke sredine $(\mathrm{X})$ za sve IK i njenih granica svih indikatora: $C L X=0,80, D K G X=0,65$, GKGX $=0,95$. Izračunata je i zbirna vrednost raspona $(\mathrm{R})$ za sve IK i njenih granica je: $C L R=0,95, D K G R=0,11$, GKGR $=0,84$. 
Analizom dobijenih vrednosti izdvajaju se grupe indikatora sa najmanjim odstupanjima u odnosu na centralnu liniju i to:

- Prvi ključni indikator iz GIK 4 čija je CLX=0,810;

- Drugi ključni indikator iz GIK 7 CLR=0,430.

Dobijena vrednost za indikator GIK 7, CLR $(0,430)$ najbliža je idealnim vrednostima date osnove raspona $(0,470)$ i poseduje najmanja odstupanja od nje, kao i minimalni obim raspona. Istovetno, indikator GIK 4, CLX $(0,810)$ daje najpribližniju vrednost predviđenoj idealnoj vrednosti u ovom modelu X $(0,80)$.

Na prikazani način su naučno-istraživačkim projektom determinisani ključni indikatori intelektualnog kapitala u grafičkim organizacijama koje uče i glase:

GIK 4 za X - Sprovođenje programa oslobađanja od nepotrebne prošlosti i proboja prema novim performansama (novi poslovni moral, privatizacija, reinženjering, ISO 9001, promena mentaliteta, nova tržišna i razvojna orjentacija, nova vizija, misija, ciljevi itd.).

GIK 7 Ra R - Primena internih i eksternih provera sistema kvaliteta za utvrđivanje neusaglašenosti za preduzimanje korektivnih i preventivnih mera i prilika za poboljšanja ili inovacije.

\section{ZAKLJUČAK}

Nakon urađenog naučno-istraživačkog projekta na bazi informacija dobijenih od vodećih grafičkih organizacija ovih prostora, determinisani su ključni indikatori intelektualnog kapitala. Primećuje se da su navedeni ključni indikatori intelektualnog kapitala (IK) u prirodnoj sinergiji i stvaraju područje za delovanje. Uzorkovane organizacije spadaju u milje organizacija koje uče. Ključni indikatori koji su determinisani predstavljaju trenutne vrednosti i kategorije okruženja. Promenom okruženja usled zahteva kupaca oni će se menjati, a time se očekuju promene i u istraživanju.

Cilj ovog istraživanja je prezentovanje modela i načina za poboljšanju kvaliteta poslovanja u grafičkoj organizaciji koja uči, prepoznavanjem ključnih indikatora intelektualnog kapitala pomoću:

a) statističke metode Kontrolna karta (SPC kao jedna od alata za ostvarivanje TQM-a);

a) kriterijumom Kontinualna poboljšanja i inovacije (krucijalni kriterijum TQM-a) kao bazom indikatora intelektualnog kapitala;

b) primenom IT u svim fazama i procesima istraživanja (integracijom: intelektualnog kapitala, računara, inte-rneta, softvera i telekomunikacija).
Naglašava se da ovaj metod mogu koristiti samo grafičke organizacije koje uče i čije je opredeljenje poslovna izvrsnost trajna orjentacija.

Kod definisanja ključnih indikatora intelektualnog kapitala (IK), preporuka je da se obrati pažnja i na atribute: definisan $\mathrm{i}$ jasan, integrativan, inovativan i primenljiv, inovacije. Navedeni atributi učvršćuju sinergijsku vezu među ključnim indikatorima intelektualnog kapitala.

\section{LITERATURA}

1. M. Heleta, (2010) TQM Modeli izvrsnosti i integrisani menadžment sistemi, Zavod za udžbenike, Beograd;

2. Jelena Đorđrvić-Boljanović, (2009), Menadžment znanja, DATASTATUS, Beograd, str.42-58;

3. N. Pavlović, Ž. Račić, (2012), Prikaz značaja komponenti intelektualnog kapitala u savremenom okruženju, www.vps.ns.ac.rs/Materijalimat794.doc (24.02.2017);

4. Boontis N. (1998), Intelectual capital: an exploration study that develops measures and models, Management Decision 36/2;

5. Manojlo Kostić, (2004), Metode i tehnike za poboljšanje kvaliteta, Beogradski univerzitet, Beograd;

6. Helmut Kipphan (2000), Handbook of Print Media, Heidelberger Druckmaschinen AG Heidelberg;

7. Stanojković Srđan, (2016), Analiza mogućnosti primene modela izvrsnosti u grafičku industriju Srbije, rad doktorske disertacije, Univerzitet Singidunum, Beograd. 